\title{
Thermodynamic Adsorption-desorption of Metolachlor and 2,4-D on Agricultural Soils
}

\author{
Rounak M. Shariff \\ Department of Chemistry, College of Science, University of Salahaddin-Erbil \\ Kurdistan Region, Iraq \\ E-mail: rounakm2000@yahoo.com
}

Received: September 16, 2011

Accepted: September 30, 2010

Published: December 1, 2011

doi:10.5539/ijc.v3n4p134

URL: http://dx.doi.org/10.5539/ijc.v3n4p134

\begin{abstract}
To investigate the thermodynamics parameters for adsorption- desorption behavior of metolachlor (nonionic herbicides) and 2,4-D (anionic herbicides) on the selected soils by using a kinetic approach. The objective of this study to investigate the rate constants and other kinetic parameters for the adsorption-desorption behavior and to elucidate the effect of temperature, the experiments were done at $10,25,40 \pm 1{ }^{\circ} \mathrm{C}$. Data from the experiments revealed that the adsorption- desorption of metolachlor and 2,4-D on the selected soil samples followed the first order rate law, and revealed that adsorption of metolachlor and 2,4-D was spontaneous exothermic, a partly physical and partly chemical in nature to some extent. Values of adsorption rate constant $\mathrm{k}_{\mathrm{a}}$ were in the range $0.853-2.263$ and $0.765-2.399$ for metolachlor and 2,4-D respectively, desorption rate constant $\mathrm{k}_{\mathrm{d}}$ were in the range 0.744 - 1.303 and 0.705 - 1.289 for metolachlor and 2,4-D respectively. By using the Arrhenius equation the activation energy of each adsorption-desorption of both pesticides were calculated. The activation energy $E_{\mathbf{a}}$ for adsorption processes followed the range $14.667-17.361 \mathrm{~kJ} \cdot \mathrm{mol}^{-1}$ and $16.053-31.088 \mathrm{~kJ} \cdot \mathrm{mol}^{-1}$ for metolachlor and 2,4-D respectively. Values of equilibrium constant $\operatorname{lnK}_{\mathrm{o}}$ were in the range $0.036-0.608$ and $0.018-0.869$ for metolachlor and 2,4-D respectively. The free energy change $\Delta \mathrm{G}^{\mathrm{o}}$ values were in the range -0.095 to -1.431 $\mathrm{kJ} \cdot \mathrm{mol}^{-1}$, and -0.048 to $-2.048 \mathrm{~kJ} \cdot \mathrm{mol}^{-1}$ for metolachlor and 2,4-D respectively. Values of enthalpy change $\Delta \mathrm{H}^{\mathrm{o}}$ followed the range -5.954 to $-13.353 \mathrm{~kJ} \cdot \mathrm{mol}^{-1}$ and -16.998 to $-42.127 \mathrm{~kJ} \cdot \mathrm{mol}^{-1}$ for metolachlor and 2,4-D respectively. The value of entropy change $\Delta \mathrm{S}^{0}$ followed the range- 16.138 to $-1.757 \mathrm{~J} \cdot \mathrm{mol}^{-1} \cdot \mathrm{K}^{-1}$, and -16.292 to $-61.292 \mathrm{~J} \cdot \mathrm{mol}^{-1} \cdot \mathrm{K}^{-1}$ for metolachlor and $2,4-\mathrm{D}$ respectively.
\end{abstract}

Keywords: Metolachlor, 2,4-D Adsorption kinetics, Adsorption thermodynamics, HPLC

\section{Introduction}

Sorption of a pesticide is governed by two processes: transport of adsorbate from the exterior bulk solution to the accessible sorption site in the interior soil matrix and formation of sorptive bonding. The former is diffusion process, and the latter is related to sorption mechanisms, such as the activation energy of sportive bonds. Either of these processes, however, can be the rate-limiting step (Singh et al., 1986; Subramaniam et al., 2005).

Temperature is an important factor governing the rate of adsorption in soil pore. The acceleration of adsorption reactions can be described by Arrhenius equation and may be used to predict the behavior of pesticides in soil (Braida et al., 2003; Evarett, 1954). The effect of temperature on the rate of hydrolysis is exemplified by the work (Smith et al., 2003; Ismail et al., 2002). The existence of a number of experiments that use a correction of solubility- temperature effect on the standard enthalpy of the pesticide adsorption processes (Di Cesari \& Smith, 1994; Cheung \& Biggar, 1974).

The main factors that controlling the sorption of herbicides by SOM include, the hydrophobicity characteristic of the adsorbent and adsorbate, and the properties of the soil system, such as clay mineral composition, $\mathrm{pH}$, kinds and amounts of exchangeable cations, moisture, and temperature (Borisover \& Graber, 1997). The observed differences in adsorption between the organic compounds in the same soil are because of difference in the physical and chemical characteristics of the compounds (Scribner et al., 1992).

The metolachlor belongs to chloroacetanilide herbicides which used in corn crops and cotton, its soluble in water, and poorly bound to most soils so it leaching down towards the ground water (Wauchope et al., 1992; Krutz et al., 2004). 
The 2,4-D as acidic herbicide is most widely used herbicide to kill or suppresses unwanted plants by its chemical structure through the herbicide's mode of action mechanism (biochemical or physical) (McCall et al., 1980; Parker \& Doxtader, 1983). Its adsorption involved ionic interaction with positive charges in soil and also the less energetic Van der Waals forces and charge transfer (Kahan, 1973; Nearpass, 1976). Thus sorption may occur as a result of enthalpy-related and entropy-related forces, hydrophobic bonding is an example of entropy driven processes; it's due to the combination of London dispersion forces. For polar chemical the second type are greater due to electrostatic interaction.

\section{Materials and Methods}

\subsection{Soils}

Fresh soil samples were taken from six main agricultural locations in Kurdistan Region, representing a wide range of physico-chemical properties. Subsamples of homogenized soils were analyzed for moisture content, organic matter content, particle size distribution, texture, $\mathrm{pH}$, loss on ignition and exchangeable basic cations. The detail was characterized in our previous article (Shariff, 2011).

\subsection{Pesticides}

Analytical grad substituted metolachlor [2-chloro-N-(2-ethyl-6-methylphenyl)-N-(2-methoxy-1-methyl) acetamide] (purity 97.8\%), and 2,4-D [2,4-dichlorophenoxyacetic acid] (purity 98\%) were purchased from Riedal-de Haen, Sigma-Aldrich company. All chemicals used were of analytical grade reagents and used without pre-treatments. Standard stock solutions of the pesticides were prepared in deionised water.

\subsection{Adsoption - Desorption Experiments}

Adsorption of the two pesticides and the effect of temperature from aqueous solution was determined at temperature $\left(10,25,40 \pm 1{ }^{\circ} \mathrm{C}\right)$ employing a standard batch equilibrium method (Kafia \& Rounak, 2009; Ahmad et al., 2001) Duplicate air-dried soil samples were equilibrated with different pesticide concentrations $(3,5,10$, and $15 \mu \mathrm{g} \cdot \mathrm{ml}^{-1}$ ) were for the two pesticides at the soil solution ratios 4:8, 5:10 for metolachlor and 2,4-D respectively, in $16 \mathrm{ml}$ glass tube fitted with Teflon-lined screw caps. The samples plus blanks (no pesticide) and control (no soil) were thermostated and placed in shaker for $0.5,1,3,6,9,12$ and $24 \mathrm{~h}$ for metolachlor and $0.5,1$, $1.5,2,2.5,3,3.5,4,6$ and $24 \mathrm{~h}$ for 2,4-D. The tubes were centrifuged for $20 \mathrm{~min}$. at $3000 \mathrm{rpm}$. One $\mathrm{ml}$ of the clear supernatant was removed and analyzed for the pesticide concentration (Kahan, 1973; Rounak \& Kafia, 2011; Suman \& Gajbhiye, 2002).

Pesticide identification was done by PerkinElmer series 200 USA family high performance liquid chromatography (HPLC). One $\mathrm{ml}$ of the clear supernatant was removed and analyzed for the pesticide concentration (Kafia \& Rounak, 2009). Pesticide identification was done by PerkinElmer series 200 USA family high performance liquid chromatography (HPLC) equipped with a changed loop $(20 \mu \mathrm{l}), \mathrm{C}_{18}$ reversed phase column, flow rate $1.0 \mathrm{ml} \cdot \mathrm{min}^{-1}$, and a variable wave length UV detector at wavelengths $220 \mathrm{~nm}$ and $200 \mathrm{~nm}$ for metolachlor and 2,4-D respectively. Separation of the two pesticides in aqueous phase was achieved with a mobile phase of at ratio of acetonitrile and water $(\mathrm{v} / \mathrm{v})$ were 80:20, 60:40 (acidified with $0.1 \%$ phosphoric acid) for metolachlor and 2,4-D respectively. Under these conditions the retention time of metolachlor, and 2,4-D was $5.37,4.69$ min respectively.

Desorption processes and the effect of temperature from aqueous solution were determined at temperature (10, $25,40 \pm 1{ }^{\circ} \mathrm{C}$ and done as each test tube was placed in a thermostated shaker after equilibration for $24 \mathrm{~h}$ with different pesticide concentrations $\left(3,5,10\right.$ and $\left.15 \mu \mathrm{g} \cdot \mathrm{ml}^{-1}\right)$ the samples were centrifuged, $5 \mathrm{ml}$ of supernatant was removed from the adsorption equilibrium solution and immediately replaced by $5 \mathrm{ml}$ of water and this were repeated for four times. The resuspended samples were shaken mentioned time previously for the kinetic study.

Each sample was injected twice to determine the pesticide content by integrating the obtained peak with the respective standard pesticides. The pesticide content was average of two measurements, with no more than $5 \%$ deviation between the measurements.

\section{Data Analysis}

\subsection{Adsorption-Desorption Kinetics}

The rate constants for adsorption of each pesticide on soils were calculated using the first order rate expression (Suman \& Gajbhiye, 2002):

$$
\log \left(C-C_{t}\right)=\log C-\frac{k}{2.303} t
$$


Where $\mathrm{k}$ is $\mathrm{k}_{\mathrm{a}}$ is the rate constant for adsorption process $\left(\mathrm{h}^{-1}\right), \mathrm{t}$ the time (hour), $\mathrm{C}$ is $\mathrm{C}_{\mathrm{o}}$ the concentration of pesticide added $\left(\mu \mathrm{g} \cdot \mathrm{ml}^{-1}\right)$ and $\mathrm{C}_{\mathrm{t}}$ the amount adsorbed $\left(\mu \mathrm{g} \cdot \mathrm{ml}^{-1}\right)$ at time $\mathrm{t}$. In all cases, first order equation provided satisfactory fit for the data as linear plots of $\log \left(\mathrm{C}_{\mathrm{o}}-\mathrm{C}_{\mathrm{t}}\right)$ against $\mathrm{t}$ (Table 1).

The same equation used to describe the process of desorption in all experiments and on all soil samples (Soledad M. et al., 2004). Where $\mathrm{k}$ is $\mathrm{k}_{\mathrm{des}}$ is the desorption rate constant $\left(\mathrm{h}^{-1}\right), \mathrm{C}_{\mathrm{t}}$ is the amount of released pesticides at time $t$ and $C$ is $C_{e}$ is the amount of released pesticides at equilibrium and $k$ is $k_{\text {des }}$ is the slope of straight line which is equal to coefficient release rate of $k_{\text {des }}$. A plot of $\log \left(C_{e}-C_{t}\right)$ versus $t$ should give a straight line with slope $-\mathrm{k}_{\mathrm{des}} / 2.303$ and intercept of $\log \mathrm{C}_{\mathrm{e}}$ of both pesticides demonstrated in (Table 1).

\subsection{Equilibrium constant}

The thermodynamic parameters associated with the adsorption processes which were calculated from the variation of the thermodynamic equilibrium constant $\mathrm{K}_{\mathrm{o}}$, with change in temperature. The equilibrium constant $\mathrm{K}_{\mathrm{o}}$ was obtained from the ratio adsorption rate constant $\mathrm{k}_{\mathrm{a}}$ to desorption rate constant $\mathrm{K}_{\text {des }}$ which enable us to calculate the thermodynamic parameters for physic-chemical equilibrium between pesticides and soil, during the adsorption reaction which can be defined as (OP. Bansal, 2004):

$$
K o=\frac{k a}{k d e s}
$$

The results were summarized in table 1 for metolachlor and 2,4-D respectively, figure1-a \&b show the Variation of $\mathrm{K}_{\mathrm{o}}$ with temperatures $\mathrm{T}$ for metolachlor and 2,4-D respectively.

\subsubsection{Arrhenius activation energy}

The Arrhenius activation energy $\mathbf{E}_{\mathbf{a}}$ for the adsorption and desorption processes for each pesticide on soils were calculated by linearised Arrhenius equation (Elkhatib et al., 2007; Chaudhary \& Prasad, 1999):

$$
\ln k=\ln A-\frac{E a}{R T}
$$

Where $\mathrm{k}$; adsorption rate constant or desorption rate constant, $\mathrm{E}_{\mathrm{a}}$; the activation energy, R; gas constant 8.314 $\mathrm{J} \cdot(\mathrm{Kmol})^{-1}$, and T; absolute temperature, A; preexponential factor. As the plot of -lnk against the reciprocal of absolute temperature resulted in straight lines for each system. The activation energies were evaluated from the slope of each linear plot as shown in table $2 \& 3$ for metolachlor and 2,4-D respectively.

\subsubsection{Activation parameters}

A plot of $\ln (\mathrm{k} / \mathrm{T})$ against the reciprocal of absolute temperature for each system, the enthalpy of activation, $\Delta \mathrm{H}^{*}$, and the entropy of activation, $\Delta \mathrm{S}^{*}$ were calculated from Eyring equation (Sparks \& Liebhardt, 1983; Sismanoglu et al., 2004):

$$
\ln \frac{k}{T}=\ln \frac{\mathbf{k}}{h}+\frac{\Delta S^{*}}{R}-\frac{\Delta H^{*}}{R T}
$$

Where k; adsorption rate constant or desorption rate constant: $\Delta \mathrm{H}^{*}$; enthalpy of activation, $\Delta \mathrm{S}^{*}$; entropy of

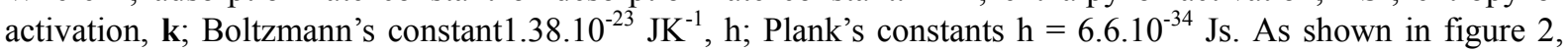
and 3 the enthalpy of activation, $\Delta \mathrm{H}^{*}$, and the entropy of activation, $\Delta \mathrm{S}^{*}$ were calculated from the slope and the intercept of each linear plot as shown in table $2 \& 3$ for metolachlor and 2,4-D respectively.

The free energies of activation, $\Delta \mathrm{G}^{*}$ for each system were determined by using the equations bellow (Lindistrom et al., 1970).

$$
\Delta G^{*}=\Delta H^{*}-T \Delta S^{*}
$$

The values of $\Delta \mathrm{G}^{*}$ were determined at a $\mathrm{T}$ value which is equal to $298.15 \mathrm{~K}$, and these values are included in table $2 \& 3$ for metolachlor and 2,4-D respectively.

\subsubsection{Isosteric enthalpy of Adsorption}

The isosteric enthalpy of adsorption is the standard enthalpy of adsorption at a fixed surface coverage. Values of isosteric heat of the adsorption as a function of the amount of the chemical adsorbed ( $\mathrm{x}$ ) was calculated by the expression (Lindistrom et al., 1970):

$$
\Delta H=R\left[\frac{d \operatorname{LnCe}}{d\left(\frac{1}{T}\right)}\right] x
$$


Where $\mathrm{C}_{\mathbf{e}}$ is the equilibrium concentration, and the average were calculated for each concentration, The results were summarized in table 4 for metolachlor and 2,4-D respectively.

\subsubsection{Standard free energy change}

Adsorptions equilibrium constant $\left(\mathrm{K}_{\mathrm{o}}\right)$, can be expressed in terms of the standard Gibbs or free energy for adsorption $\left(\Delta \mathrm{G}^{\mathrm{o}}\right)$ (Rounak \& Kafia, 2011).

$$
\Delta G^{o}=-R T L n K o
$$

The results were summarized in table $5 \& 6$ for metolachlor and 2,4-D respectively.

\subsubsection{Standard enthalpy and entropy change}

The standard enthalpy change of adsorption $\left(\Delta \mathrm{H}^{\circ}\right)$ represents the difference in binding energies between the solvent and the soil with the pesticides. Values of $\Delta \mathrm{H}^{\circ}$ and standard entropy change $\left(\Delta \mathrm{S}^{\circ}\right)$ also determined graphically from the following equation (Rounak \& Kafia, 2011; Young et al., 2004):

$$
\operatorname{LnKo}=\frac{\Delta H^{o}}{R T}+\frac{\Delta S^{o}}{R}
$$

Plotting - $\ln \mathrm{K}_{\mathrm{o}}$ against $1 / \mathrm{T}$, a straight line is expected the standard enthalpy change $\left(\Delta \mathrm{H}^{\circ}\right)$ of adsorption were determined from the slope, and the intercept equal to $\Delta S^{\circ} / R$. The results were summarized in table 7 .

\section{Results and Discussion}

\subsection{Arrhenius activation parameters}

Values of adsorption rate constant $k_{a}$ were in the range $0.853-2.263$ and $0.765-2.399$ for metolachlor and 2,4-D respectively, desorption rate constant $\mathrm{k}_{\mathrm{d}}$ were in the range $0.744-1.303$ and $0.705-1.289$ for metolachlor and 2,4-D respectively. The Values of adsorption rate constant for metolachlor and 2,4-D on selected soil samples were in were greater than the desorption constant for Metolachlor and 2,4-D on selected soil samples. Indicating that adsorption processes was faster than the desorption for metolachlor and 2,4-D, due to the characteristics of each pesticide and their interactions with soil constituents (Bansal, 2004). The Values of adsorption-desorption rate constant for metolachlor and 2,4-D on selected soil samples decreased by increasing the temperature.

By using the Arrhenius equation the activation energy of each adsorption-desorption of both pesticides were calculated. The activation energy $E_{a}$ for adsorption processes followed the range $14.667-17.361 \mathrm{~kJ} \cdot \mathrm{mol}^{-1}$ and $16.053-31.088 \mathrm{~kJ} \cdot \mathrm{mol}^{-1}$ for metolachlor and 2,4-D respectively. While for desorption processes followed the range $3.635-8.796 \mathrm{~kJ} \cdot \mathrm{mol}^{-1}$ and $4.034-12.339 \mathrm{~kJ} \cdot \mathrm{mol}^{-1}$ for metolachlor and 2,4-D respectively, and the values of $\mathrm{R}^{2}$ in range 0.862 to 0.999 for metolachlor and 0.849 to 0.999 for 2,4-D. As the values of $\mathrm{E}_{\mathrm{a}}$ for adsorption processes were higher than desorption. $\mathrm{E}_{\mathrm{a}}$ for physical must be low $(10-28 \mathrm{~kJ})$ and high $(30-40 \mathrm{~kJ})$ for chemisorption. The values of $E_{a}$ also supported the order of pesticides adsorption on soil samples. The adsorption rate constant and amount adsorbed increased with the increase in organic matter content of soil, indicating that the adsorption occurred via organic matter (Bansal, 2004). The highest activation energy, the stronger temperature dependence of the rate constant. That is, a high activation energy signifies that the rate constant changes rapidly with temperature (Lindistrom et al., 1970).

The enthalpy of activation, $\Delta \mathrm{H}^{*}$ for adsorption-desorption were calculated from Eyring equation (4). Values of $\Delta \mathrm{H}^{*}$ followed the range -16.728 to $-19.463 \mathrm{~kJ} \cdot \mathrm{mol}^{-1}$, -6.109 to $-11.269 \mathrm{~kJ} \cdot \mathrm{mol}^{-1}$ for adsorption-desorption of metolachlor respectively. Values of $\Delta \mathrm{H}^{*}$ followed the range -18.526 to $-28.573 \mathrm{~kJ} \cdot \mathrm{mol}^{-1},-14.813$ to -6.508 $\mathrm{kJ} \cdot \mathrm{mol}^{-1}$ for adsorption-desorption of 2,4-D respectively. The negative values of $\Delta \mathrm{H}^{*}$ indicated the possibility of a chemisorptions. The most probable nature of the adsorption was physical type, and a hydrogen bond formation was suggested to explain the higher value (Sismanoglu, 2004).

The values of isosteric enthalpy of adsorption were followed the range $981.579-1,076.642 \mathrm{~kJ} \cdot \mathrm{mol}^{-1}, 880.401$ $1,405.050 \mathrm{~kJ} \cdot \mathrm{mol}^{-1}$ for Metolachlor and 2,4-D respectively on selected soil samples. The values of isosteric heat of adsorption as a function of amount of chemical adsorbed was almost the same for all the both pesticides on six soils that support our inference regarding the mechanism of adsorption. These values were relatively small and were of the order which was consistent with a physical type of adsorption (Young et al., 2004).

The values of entropy of activation $\Delta \mathrm{S}^{*}$ followed the range -297.93 to $-309.68 \mathrm{~J} \cdot \mathrm{mol}^{-1} \cdot \mathrm{k}^{-1},-265.67$ to -283.37 $\mathrm{J} \cdot \mathrm{mol}^{-1} \cdot \mathrm{k}^{-1}$ for adsorption-desorption of metolachlor respectively. While the values followed the range -304.675 to $-338.912 \mathrm{~J} \cdot \mathrm{mol}^{-1} \cdot \mathrm{k}^{-1}$ and -266.149 to -294.931 for adsorption-desorption of 2,4-D respectively. The negative values pointing to the formation of an activated complex by coordination or association of the both pesticides and exchangeable cation with results loss in the degree of freedom of the pesticide (Yang et al., 2003; Griffin \& 
Jurinak, 1973).

The values of free energy change $\Delta \mathrm{G}^{*}$ for adsorption of the studied pesticides on the selected soil samples at 283.15, 298.15 and $313.15 \mathrm{~K}$ were summarized in tables $2 \& 3$ for metolachlor and 2,4-D respectively. The values of $\Delta \mathrm{G}^{*}$ for adsorption of studied pesticides were negative and decreased with the rise in temperature, which due to the formation of an activated complex as $\Delta \mathrm{G}^{*}$ represents the energy barrier and governs the reaction rate (Lindistrom et al., 1970). The $\Delta \mathrm{G}^{*}$ values were in the range -102.87 to $-109.38 \mathrm{~kJ} \cdot \mathrm{mol}^{-1}$, and -82.926 to $-93.204 \mathrm{~kJ} \cdot \mathrm{mol}^{-1}$ for adsorption-desorption of metolachlor respectively. The $\Delta \mathrm{G}^{*}$ values were in the range -106.624 to $-126.569 \mathrm{~kJ} \cdot \mathrm{mol}^{-1}-83.465$ to $-100.092 \mathrm{~kJ}^{-} \mathrm{mol}^{-1}$ for adsorption-desorption of 2,4-D respectively.

\subsection{Equilibrium constant}

Equilibrium constant $\mathrm{K}_{\mathrm{o}}$ : It is well known that $\mathrm{K}_{\mathrm{o}}$ is constant at constant temperature and the position of equilibrium depends only on thermodynamic quantities and is independent of any consideration of kinetics or mechanism. The large difference in the equilibrium adsorption arise mainly from the difference in the rate of desorption. Values of equilibrium constant $\mathrm{K}_{\mathrm{o}}$ conducted by the ratio between the rate of adsorption rate to the rate of desorption (Bansal, 2004; Gupta et al., 2004), equilibrium constant for metolachlor and 2,4-D on selected soil samples respectively. The values of thermodynamic equilibrium constant, in all cases; are summarized in table $5 \&$ 6. Values of equilibrium constant $\operatorname{lnK}_{\mathrm{o}}$ were in the range $0.036-0.608$ and $0.018-0.869$ for metolachlor and 2,4-D respectively. Values of $\mathrm{K}_{\mathrm{o}}$ obtained can vary among soils due to the quantities and composition of soil components. The $\mathrm{K}_{\mathrm{o}}$ values were decreased with rise in temperature as in fig $1 \mathrm{a} \& \mathrm{~b}$, confirming that the pesticides had a high preference for adsorption at low temperature.

The values of $\Delta \mathrm{G}^{\circ}$ for adsorption of studied pesticides were negative and decreased with the rise in temperature, indicating that at all experimental temperatures; the interactions of pesticides on soils were spontaneous with a high preference of the soil surface. The magnitude of $\Delta \mathrm{G}^{0}$ also showed that the interactions of pesticides with the soil were thermodynamically spontaneous process and adsorption occurred through a bonding mechanism. The free energy change $\Delta \mathrm{G}^{\mathrm{o}}$ values were in the range -0.095 to $-1.431 \mathrm{~kJ} \cdot \mathrm{mol}^{-1}$, and -0.048 to $-2.048 \mathrm{~kJ} \cdot \mathrm{mol}^{-1}$ for metolachlor and 2,4-D respectively. At constant temperature, the higher the value of $\Delta \mathrm{G}^{\mathrm{o}}$ the slower is the rate of adsorption. The values of $\Delta \mathrm{G}^{\circ}$ increased with rise in temperature. The results obtained in the present study are similar to those of Gupta, et al. (Gupta, 2004) who reported an increase in the values of $\Delta \mathrm{G}^{\mathrm{o}}$ with temperature. Variation of $\Delta \mathrm{G}^{\mathrm{o}}$ with temperature may be due to the increase in the degree of freedom of adsorbed molecules, which enhances the desorption rather than adsorption at higher temperatures (Michael Sander et al., 2005; Alexandre G. S. Prado et al., 2004). This indicates that the adsorption process is spontaneous, in all temperature and for the both pesticides.

The values of enthalpy change $\Delta \mathrm{H}^{\mathrm{o}}$ followed the range -5.954 to $-13.353 \mathrm{~kJ} \cdot \mathrm{mol}^{-1}$ and -16.998 to -42.127 $\mathrm{kJ} \cdot \mathrm{mol}^{-1}$ for metolachlor and 2,4-D respectively. The results were summarized in table 7 . The negative values of $\Delta \mathrm{H}^{\mathrm{o}}$ indicated the exothermic behaviors of the reaction, as the temperature increases the negative values of $\Delta \mathrm{H}^{\circ}$ is decreased. The linear nature of the plot indicates that the mechanism of adsorption is not changed as temperature is changed. The values of $\mathrm{R}^{2}$ were in the range 0.889 to 0.999 , and 0.883 to 0.990 for metolachlor and 2,4-D respectively which supported the linear nature of the plot. The amount of energy released during adsorption is changed because the supply of thermal energy is different.

The negative enthalpy of adsorption for partition coefficient, indicating an exothermic binding reaction (Swanson \& Dutt, 1973), showing that the interaction of pesticides with the soil is an energetically stable exothermic process and the adsorption occurred through a bonding mechanism. The $\Delta \mathrm{H}^{\mathrm{o}}$ values explained the binding strength of pesticides to the soil. The lower negative value of $\Delta \mathrm{H}^{\circ}$ indicates stronger binding. The different values of $\Delta \mathrm{H}^{\mathrm{o}}$ for adsorption of the same pesticide on the selected soils may be correlated to differences in soil constituents. Thus low values of $\Delta \mathrm{H}^{\circ}$ pointed towered chemisorptions, hence the herbicides adsorption may be due to coordination and /or protonation, hydrogen bonding and dipole association or van der Waal's forces, and metal ion bridged mechanism between the clay and / or organic molecules occur with or without a water bridge. Our results showed that the negative values of $\Delta \mathrm{H}^{\circ}$ decrease with temperature. This indicates that the interactions between the pesticides and the studied soil samples were stronger at lower temperature. The exothermic nature of the adsorption process of all six soil samples shows that these processes are energetically stable consistent with a physical type of adsorption.

The results were summarized in table 7 where $\Delta \mathrm{S}^{0}$ followed the range. The value of entropy change $\Delta \mathrm{S}^{0}$ followed the range- 16.138 to $-1.757 \mathrm{~J} \cdot \mathrm{mol}^{-1} \cdot \mathrm{k}^{-1}$, and -16.292 to $-61.292 \mathrm{~J} \cdot \mathrm{mol}^{-1} \cdot \mathrm{k}^{-1}$ for metolachlor and 2,4-D respectively. A negative slope of equation 6 means that $\operatorname{lnK}_{0}, \mathrm{~K}_{\mathrm{o}}$ itself, decreases as the temperature rises in the case of metolachlor and 2,4-D. Therefore, in the case of exothermic reaction the equilibrium shifts a way from 
adsorption of some insight into the thermodynamic basis of this behavior which can be found in the equation 6 when the reaction is exothermic, $-\Delta \mathrm{H}^{\mathrm{o}} / \mathrm{T}$ corresponds to positive change of entropy of the surroundings, and favors the adsorption. When temperature is raised $-\Delta \mathrm{H}^{\circ} / \mathrm{T}$ decreases and the increasing entropy of the surroundings which has a less potent role. As a result, the equilibrium lies less to the adsorption process. The negative values of $\Delta \mathrm{S}^{\mathrm{o}}$ indicate that the adsorption complexes of the herbicide formed on all six soil samples were stabilization, Association, fixation or immobilization of the pesticides molecules as a result of adsorption decreased the degree of freedom, causing negative entropy effect (Hundal \& Pasricha, 1994; Alam et al., 2005). The changes in the standard entropy $\left(\Delta \mathrm{S}^{\circ}\right)$ of adsorption suggest a formation of ion-ion and hydrophobic interactions in the higher spacing, resulting in the decrease in the standard entropy (Jana.T. K. \& Das B., 1997; Adlophe Monkiedje \& Micheal Spiteller, 2002).

The values of entropy reflected how it's a function for disorder, at all the experimental temperatures. The values of entropies pointing to the formation of the complexity by; coordination or association of the herbicides and an exchangeable cation with the resultant of the loss in the degree of freedom of the pesticide. The negative values of $\Delta \mathrm{S}^{\mathrm{o}}$ decreased with the increasing of temperature indicated that the reaction is spontaneous and exothermic, for all the both pesticides and this supported our results that the increase of the temperature from 288.15 to $308.15 \mathrm{~K}$ leads to increase the thermal energy for the reactant and products combined with the decrease in the rate of adsorption reaction. On the other side, the increase in the thermal energy of the reactant and product leads to increase the disorder of reactant and product which decrease the bond energy formation for products of the reaction (adsorption).

\section{Conclusion}

To understand the basic reactions in soils, the knowledge of kinetics and thermodynamics is essential. Unfortunately, thermodynamics and kinetic investigations of clay and soils are limited. This is particularly true for soils that contain complex mixtures of clay minerals, non-crystalline components, oxides, hydroxides and organic matter. Adsorption experiments were conducted at 10,25 , and $40{ }^{\circ} \mathrm{C}$ to study the thermodynamic (equilibrium) parameter, associated with the adsorption of the studied pesticides on the selected soil samples.

\section{References}

A. Bala Subramaniam, C. Mejean, M. Abkarian, \& H. A. Stone. (2005). Microstructure, Morphology and Lifetime, of Armored Bubbles Exposed to Surfactants. J. Colloids, Bubbles and Surfactant. Environ., 4, 553-556.

Adlophe Monkiedje, \& Micheal Spiteller. (2002). Fungicides, Mefenoxam and Meta Laxly, and their Acid Metabolite in Typical Cameroonian and German Soils. Chemosphere, 49, 659-668. http://dx.doi.org/10.1016/S0045-6535(02)00325-9

Alexandre G. S. Prado, Andreia H. Tosta, \& Glaudio Airoldi. (2004). A sorption, Separation, and Thermodynamic Data on Herbicide Picloram Adsorbed on Silica Gel and its Cation Interaction Behavior. Journal of Colloidal and Interface Science, 269, 259-264. http://dx.doi.org/10.1016/S0021-9797(03)00685-4

B. S. Ismail, A. O. S. Enoma, U. B. Cheah, K. Y. Lum, \& Zulkifli Malik. (2002). Adsorption, Desorption, and Mobility of Two Insecticides in Malaysian Agricultural Soil. J. Environ. Sci. Health, B37, 355-364. http://dx.doi.org/10.1081/PFC-120004476

Bao-ling chen., Lizhong zhu, \& Shu Tao. (2005). Thermodynamics of Phenantherene Partition into Solid Organic Matter From Water. Journal of Environmental Science, 17, 185-189.

Braida, W. J., J.J. Pignatello, Y. Lu, P.I. Ravikovitch, A. V. Neimark, \& B. Xing. (2003). Sorption Hysteresis of Benzene in Charcoal Particles. Environ. Sci. Technol., 37, 409-417. http://dx.doi.org/10.1021/es020660z

D. L. Sparks, \& W. C. Liebhardt. (1983). Temperature Effects on Potassium Exchange and Selectivity in Delaware Soils. Dotash Review, 4, 1-9.

Di Cesari, D., \& Smith, J. A. (1994). Surfactant Effects on Desorption Rate of Nonionic Organic Compounds from Soils to Water. Rev. Environ. Contam. Toxicol, 134, 1-29.

Elsayed A. Elkhatib, A. M. Mahdy, \& N. H. Bbrakat. (2007). Thermodynamics of Copper Desorption from Soils as Affected by Citrate and Succinate. Soil \& Water Res., 2, 135-140.

Evarett, D.H. (1954). A General Approach to Hysteresis, Part 4. An Alternative Formulation of the Dimain model. Trans. Faraday Soc., 51, 1551-1557. http://dx.doi.org/10.1039/tf9555101551

F. T. Lindistrom, R. Haque, \& W. R. Coshow. (1970). Adsorption from Solution. III Anew Model for Kinetics of Adsorption-Desorption Processes. J. Physical Chemistry, 74, 705. 
G. Suman, \& V. T. Gajbhiye. (2002). Adsorption -Desorption, Presestance, and Leaching Beahavior of Dithiopyr in an Auuvial soil of India. J. of Environ. Sci. and health, B37(6), 573-586. http://dx.doi.org/10.1081/PFC-120015440

H. K. Gupta, Devprakash, P. K. M. Ishra, \& vishal pathak. (2004). Studies on the Kinetics and Thermodynamics of Adsorption of Cypermethrin on Montmorillonite Clays. Asian Journal of Chemistry, 16, 1391-1397.

J.B. Alam, A. K. Dikshit, \& M. Bandy Opadhayay. (2005). Evaluation of Thermodynamic Properties of Sorption of 2,4-D and Atrazine by Trirubber Gramules. Sepration and Purification Technology, 42, 80-40. http://dx.doi.org/10.1016/j.seppur.2004.06.006

Jana.T. K., \& Das B. (1997). Sorption of carbaryl (12-naphthyl N-methyl carbamte) by Soil. Bull. Environ contam. Toxicol, 59, 65-71. http://dx.doi.org/10.1007/s001289900444

K. Chaudhary, \& B. Prasad. (1999). Thermodynamics of Potassium Exchange Reaction in Entisol and vertisol using a Kinetic Approach by Miscible Displacement Technique. Journal of the Indian Society of Soil Science, 47, 221-229.

Kahan, S. (1973). Equilibrium and Kinetic Studies of the Adsorption Studies of the Adsorption of 2,4-D and Picloram on Humic Acid. Canadian Journal of soil Science, 53, 429-434. http://dx.doi.org/10.4141/cjss73-060

L. J. Krutz, S. A. Senseman, K. J. Mclnnes, D. W. Hoffman, \& D. P. Tierney. (2004). Adsorption an Desorption of Metolachlor and Metolachlor Metabolites in Vegetated Filter Strip and Cultivated Soil. J. Environ. Qual., 33, 939-945. http://dx.doi.org/10.2134/jeq2004.0939

L. S. Hundal, \& N. S. Pasricha. (1994). Thermodynamic Parameters of Potassium Exchange as Characterized by Equilibrium and Kinetic Approaches in Chloride and Perchlorate Background Anions. Soil Science, 157, 356-363. http://dx.doi.org/10.1097/00010694-199406000-00004

M. Kafia, \& M. Rounak. (2009). Adsorption of Herbicides on eight Agricultural Soils. J. of university of anbar for pure since, 3, 67-75.

M. Rounak, \& M. Kafia. (2011). Thermodynamic Adsorption of Herbicides on eight Agricultural Soils. International Journal of Scientific \& Engineering Research, 2(6), 2229-5518.

M. Rounak Shariff. (2011). Compost Adsorption Desorption of Picloram in the Presence of Surfactant on Six Agricultural Soils. International Journal of Scientific \& Engineering Research, 2(5), 2229-5518.

M.D. Borisover, \& E. R. Graber. (1997). Competitive Sorption between Atrazine and Organic Compounds in Soil and Model Sorbents. J. Environ. Sci. Technol., 31, 1577-1577. http://dx.doi.org/10.1021/es9700111

Max W. Cheung, \& James W. Biggar. (1974). Solubility and Molecular Structure of 4-Amino-3,5,6-Trichloropiclinic Acid in Relation to $\mathrm{pH}$ and Temperature. J. Agr. Food Chemistry, 22, 202-212. http://dx.doi.org/10.1021/jf60192a047

McCall, P. J., S. A. Vron, \& S. S. Kelly. (1980). Fate of uniformly carbon-14 ring labeld 2,4,5Trichlorophenoxyacetic acid and 2,4-Dichrlorophenoxyacetic acid. J. Agric. Food Chem., 29, 100-107. http://dx.doi.org/10.1021/jf00103a026

Michael Sander, Yuefeng Lu, \& Josseph J. Pingnatello. (2005). A Thermodynamically Based method to Quantify Trine Sorption Hystersis. J. Environ. Qual., 34, 1063-1072. http://dx.doi.org/10.2134/jeq2004.0301

Nearpass, D.C. (1976). Adsorption of Picloram by Humic Acids and Humin. Soil Sci., 121, 272-277. http://dx.doi.org/10.1097/00010694-197605000-00003

OP. Bansal. (2004). Kinetics of Interaction of three Carbamate Pesticides with Indian soils: Aligarh district. Pest Manage Sci., 60, 1149-1155. http://dx.doi.org/10.1002/ps.915

Parker, L. W., \& K. G. Doxtader. (1983). Kinetics of microbial degradation of 2,4-D in soil: effects of temperature and moisture. J. Environ. Qual., $12, \quad$ 553-558. http://dx.doi.org/10.2134/jeq1983.00472425001200040024x

R. A. Griffin, \& J. J. Jurinak. (1973). Test of a New Model for the Kinetics of Adsorption-Desorption Processes. Soil Sci. Soc. Amer. Proc, 37, 869-872. http://dx.doi.org/10.2136/sssaj1973.03615995003700060023x

R. Ahmad, R.S. Kookana, \& A.M. Alston. (2001). Bulletin of Environ Contaminate and toxicol., 66, 313-318.

Roger A. Swanson, \& Gordon R. Dutt. (1973). Chemical and Physical Processes that Affect Atrazine and Distribution in Soil Systems. Soil Sci. Soc. Amer. Proc, 37, 872-876. http://dx.doi.org/10.2136/sssaj1973.03615995003700060024x 
Scribner, S. L., T. R. Benzing. S. Sun, \& S. A. Boyd. (1992). Desorption and Bioavailability of aged Simazine Residues in Soil from Continuous Field. J. Environ. Qual., 21, 115-120. http://dx.doi.org/10.2134/jeq1992.00472425002100010017x

Singh, U.S., Tripathi, R.K.; Kumar, J., \& Dwivedi, T.S. (1986). Uptake, Translocation, Distribution and Persistence of Metalaxyl i.e, Pearl Millet (Pennisetum Americanum (L) Lecke.). T. Phytopathol, 117, 112-115.

Smith, M.C., D.R., Shaw, J.H. Wassey, M. Boyette, \& W. Kingery. (2003). Using Nonequilibrium Thin-disc and Batch Equilibrium Techniques to Evaluate Herbicide Sorption. J. Environ. Qual., 32, 1393-1404. http://dx.doi.org/10.2134/jeq2003.1393

Soledad M., Andades R., Sonia Rodri Guez-Cruz M., Jesus Sanchez-Martin M., \& Maria Sanchez-Camazano, January-March. (2004). Effect of the Modification of Natural Clay Minerals with Hexadecylpyridinium Cation on the Adsorption-Desorption of Fungicides. Intern. J. Environ. Anal. Chem., 84, 133-141. http://dx.doi.org/10.1080/03067310310001593701

T. Sismanoglu, A. Ercage, S. Pura, \& E. Ercage (2004). Kinetics and Isotherms of Dazomet Adsorption on Natural Adsorbents. J. Braz. Chem. Soc., 15, 669-675. http://dx.doi.org/10.1590/S0103-50532004000500010

Wauchope, R. D., Buttler., T. M. Hornsby A. G., Augustijn-Beckers, P. W. M., \& Burt, J. P. (1992). SCS/ARS/CES "pesticide properties database for environmental decisionmaking". Reviews of Environment Contamination and Toxicology, 123, 1-157, 8-2.

Yang Wei-chun, Liu Wei-ping, Liu Hui-jun, \& Liu Guang -shen. (2003). Adsorption and Correlation with Thermodynamic Properties of Triazine Herbicides on Soils. Journal of Environmental Science, 15, 443-448.

Young -HakKim, Thomas M. Heinze, Seong-Jae Kim, \& Carl E. Cerniglia. (2004). Adsorption and Clay Catalized Degradation of Erythromycin A on Homoionic Clays. J. Environ. Qual., 33, 257-264.

Table 1. Adsorption rate constants $k_{a}$, desorption rate constants $k_{d}$ and equilibrium rate constants $k_{o}$ for metolachlor and 2,4-D on the selected soil samples

\begin{tabular}{|c|c|c|c|c|c|c|c|c|}
\hline \multirow{2}{*}{ pesticides } & \multirow{2}{*}{ Temp(K) } & \multirow{2}{*}{ Parameter } & \multicolumn{6}{|c|}{ Soils } \\
\hline & & & $\mathrm{S}_{1}$ & $\mathrm{~S}_{2}$ & $\mathrm{~S}_{3}$ & $\mathrm{~S}_{4}$ & $\mathrm{~S}_{5}$ & $\mathrm{~S}_{6}$ \\
\hline \multirow{9}{*}{ Metolachlor } & \multirow{3}{*}{283.15} & $\mathrm{k}_{\mathrm{a}}(\mathrm{calc})$ & 1.783 & 2.108 & 1.916 & 1.911 & 1.735 & 2.263 \\
\hline & & $\mathrm{k}_{\mathrm{d}}($ calc $)$ & 1.073 & 1.164 & 1.276 & 1.041 & 1.003 & 1.303 \\
\hline & & $\mathrm{K}_{\mathrm{o}}$ & 1.662 & 1.811 & 1.502 & 1.836 & 1.729 & 1.737 \\
\hline & \multirow{3}{*}{$298.15 \mathrm{~K}$} & $\mathrm{k}_{\mathrm{a}}(\mathrm{calc})$ & 1.366 & 1.502 & 1.532 & 1.348 & 1.326 & 1.696 \\
\hline & & $\mathrm{k}_{\mathrm{d}}(\mathrm{calc})$ & 1.004 & 1.117 & 1.123 & 0.984 & 0.914 & 1.079 \\
\hline & & $\mathrm{K}_{\mathrm{o}}$ & 1.360 & 1.345 & 1.364 & 1.370 & 1.449 & 1.572 \\
\hline & \multirow{3}{*}{$313.15 \mathrm{~K}$} & $\mathrm{k}_{\mathrm{a}}$ (calc) & 0.977 & 1.162 & 1.069 & 0.957 & 0.853 & 1.158 \\
\hline & & $\mathrm{k}_{\mathrm{d}}(\mathrm{calc})$ & 0.747 & 0.956 & 1.031 & 0.897 & 0.744 & 1.042 \\
\hline & & $\mathrm{K}_{\mathrm{o}}$ & 1.308 & 1.215 & 1.037 & 1.067 & 1.146 & 1.111 \\
\hline \multirow{9}{*}{ 2,4-D } & \multirow{3}{*}{283.15} & $\mathrm{k}_{\mathrm{a}}$ (calc) & 1.942 & 2.289 & 2.399 & 2.210 & 2.209 & 2.134 \\
\hline & & $\mathrm{k}_{\mathrm{d}}(\mathrm{calc})$ & 1.173 & 1.289 & 1.164 & 1.220 & 0.925 & 1.235 \\
\hline & & $\mathrm{K}_{\mathrm{o}}$ & 1.659 & 1.774 & 2.009 & 1.811 & 2.387 & 1.729 \\
\hline & \multirow{3}{*}{$298.15 \mathrm{~K}$} & $\mathrm{k}_{\mathrm{a}}$ (calc) & 1.239 & 1.433 & 1.661 & 1.747 & 1.213 & 1.475 \\
\hline & & $\mathrm{k}_{\mathrm{d}}(\mathrm{calc})$ & 1.071 & 1.178 & 0.974 & 1.038 & 0.885 & 0.987 \\
\hline & & $\mathrm{K}_{\mathrm{o}}$ & 1.157 & 1.216 & 1.706 & 1.683 & 1.369 & 1.494 \\
\hline & \multirow{3}{*}{$313.15 \mathrm{~K}$} & $\mathrm{k}_{\mathrm{a}}$ (calc) & 1.014 & 0.943 & 0.977 & 0.952 & 0.765 & 1.016 \\
\hline & & $\mathrm{k}_{\mathrm{d}}(\mathrm{calc})$ & 0.995 & 0.865 & 0.863 & 0.741 & 0.705 & 0.746 \\
\hline & & $\mathrm{K}_{\mathrm{o}}$ & 1.019 & 1.090 & 1.131 & 1.284 & 1.085 & 1.362 \\
\hline
\end{tabular}


Table 2. Thermodynamic parameters for the adsorption-desorption change at three temperatures for adsorption of metolachlor on the selected soil samples

\begin{tabular}{|c|c|c|c|c|c|c|c|c|}
\hline \multirow{2}{*}{ Soil } & \multicolumn{2}{|c|}{$E_{a}\left(k J \cdot \mathrm{mol}^{-1}\right), R^{2}$} & \multicolumn{2}{|c|}{$\Delta \mathrm{H}_{\mathrm{a}}\left(\mathrm{kJ} \cdot \mathrm{mol}^{-1}\right), \mathrm{R}^{2}$} & \multicolumn{2}{|c|}{$\Delta \mathrm{S}_{\mathrm{a}}\left(\mathrm{J} \cdot \mathrm{mol}^{-1} \cdot \mathrm{K}^{-1}\right)$} & \multicolumn{2}{|c|}{$\Delta \mathrm{G}_{\mathrm{a}}\left(\mathrm{kJ} \cdot \mathrm{mol}^{-1}\right)$} \\
\hline & Adsorption & Desorption & Adsorption & Desorption & Adsorption & Desorption & Adsorption & Desorption \\
\hline $\mathrm{S}_{1}$ & $\begin{array}{c}-14.750 \\
0.991\end{array}$ & $\begin{array}{c}-8.796 \\
0.862\end{array}$ & $\begin{array}{c}-17.223 \\
0.993\end{array}$ & $\begin{array}{c}-11.269 \\
0.909\end{array}$ & -300.37 & -283.37 & -104.07 & -93.204 \\
\hline $\mathrm{S}_{2}$ & $\begin{array}{c}-14.667 \\
0.998\end{array}$ & $\begin{array}{c}-4.783 \\
0.880\end{array}$ & $\begin{array}{c}-17.140 \\
0.998\end{array}$ & $\begin{array}{c}-7.256 \\
0.942\end{array}$ & -298.88 & -268.68 & -103.56 & -84.945 \\
\hline $\mathrm{S}_{3}$ & $\begin{array}{c}-14.254 \\
0.974\end{array}$ & $\begin{array}{c}-5.283 \\
0.993\end{array}$ & $\begin{array}{c}-16.728 \\
0.980\end{array}$ & $\begin{array}{c}-7.712 \\
0.997\end{array}$ & -297.93 & -269.73 & -102.87 & -85.705 \\
\hline $\mathrm{S}_{4}$ & $\begin{array}{c}-16.989 \\
0.999\end{array}$ & $\begin{array}{c}-3.635 \\
0.971\end{array}$ & $\begin{array}{c}-19.463 \\
0.999\end{array}$ & $\begin{array}{l}-6.109 \\
0.988\end{array}$ & -307.79 & -265.67 & -108.46 & -82.926 \\
\hline $\mathrm{S}_{5}$ & $\begin{array}{c}-17.361 \\
0.972\end{array}$ & $\begin{array}{c}-7.294 \\
0.941\end{array}$ & $\begin{array}{c}-19.834 \\
0.978\end{array}$ & $\begin{array}{l}-9.768 \\
0.965\end{array}$ & -309.68 & -278.78 & -109.38 & -90.376 \\
\hline $\mathrm{S}_{6}$ & $\begin{array}{c}-16.427 \\
0.988\end{array}$ & $\begin{array}{c}-5.545 \\
0.885\end{array}$ & $\begin{array}{c}-18.900 \\
0.991\end{array}$ & $\begin{array}{c}-8.019 \\
0.946\end{array}$ & -304.27 & -270.79 & -106.88 & -86.317 \\
\hline
\end{tabular}

Table 3. Thermodynamic parameters for the adsorption-desorption change at three temperatures for adsorption of 2,4-D on the selected soil samples

\begin{tabular}{|c|c|c|c|c|c|c|c|c|}
\hline \multirow{2}{*}{ Soil } & \multicolumn{2}{|c|}{$\mathrm{E}_{\mathrm{a}}\left(\mathrm{kJ} \cdot \mathrm{mol}^{-1}\right), \mathrm{R}^{2}$} & \multicolumn{2}{|c|}{$\Delta \mathrm{H}_{\mathrm{a}}\left(\mathrm{kJ} \cdot \mathrm{mol}^{-1}\right), \mathrm{R}^{2}$} & \multicolumn{2}{|c|}{$\Delta \mathrm{S}_{\mathrm{a}}\left(\mathrm{J} \cdot \mathrm{mol}^{-1} \cdot \mathrm{K}^{-1}\right)$} & \multicolumn{2}{|c|}{$\Delta \mathrm{G}_{\mathrm{a}}\left(\mathrm{kJ} \cdot \mathrm{mol}^{-1}\right)$} \\
\hline & Adsorption & Desorption & Adsorption & Desorption & Adsorption & Desorption & Adsorption & Desorption \\
\hline $\mathrm{S}_{1}$ & $\begin{array}{c}16.052 \\
0.965\end{array}$ & $\begin{array}{l}4.034 \\
0.999\end{array}$ & $\begin{array}{c}-18.526 \\
0.974\end{array}$ & $\begin{array}{c}-6.508 \\
0.999\end{array}$ & -304.675 & -266.149 & -106.624 & -83.465 \\
\hline $\mathrm{S}_{2}$ & $\begin{array}{c}21.797 \\
0.999\end{array}$ & $\begin{array}{l}9.722 \\
0.892\end{array}$ & $\begin{array}{c}-24.270 \\
0.999\end{array}$ & $\begin{array}{c}-12.196 \\
0.927\end{array}$ & -323.315 & -285.120 & -117.757 & -94.638 \\
\hline $\mathrm{S}_{3}$ & $\begin{array}{c}21.372 \\
0.977\end{array}$ & $\begin{array}{l}7.351 \\
0.993\end{array}$ & $\begin{array}{c}-23.846 \\
0.981\end{array}$ & $\begin{array}{c}-9.825 \\
0.997\end{array}$ & -321.319 & -277.970 & -116.756 & -90.200 \\
\hline $\mathrm{S}_{4}$ & $\begin{array}{c}20.523 \\
0.924\end{array}$ & $\begin{array}{c}12.168 \\
0.948\end{array}$ & $\begin{array}{c}-22.997 \\
0.938\end{array}$ & $\begin{array}{c}-14.640 \\
0.963\end{array}$ & -318.559 & -294.266 & -115.107 & -99.727 \\
\hline $\mathrm{S}_{5}$ & $\begin{array}{c}31.0880 .99 \\
8\end{array}$ & $\begin{array}{l}6.609 \\
0.849\end{array}$ & $\begin{array}{c}-28.573 \\
0.998\end{array}$ & $\begin{array}{c}-9.082 \\
0.912\end{array}$ & -338.912 & -276.936 & -126.569 & -89.158 \\
\hline $\mathrm{S}_{6}$ & $\begin{array}{c}18.226 \\
0.999\end{array}$ & $\begin{array}{c}12.339 \\
0.991\end{array}$ & $\begin{array}{c}-20.699 \\
0.999\end{array}$ & $\begin{array}{c}-14.813 \\
0.994\end{array}$ & -311.226 & -294.931 & -110.690 & -100.092 \\
\hline
\end{tabular}


Table 4. Isosteric heat change of adsorption of metolachlor and 2,4-D on the selected soil samples

\begin{tabular}{|c|c|c|}
\hline Soil & $\begin{array}{c}\text { metolachlor } \\
\text { average } \mathrm{X}(\mathrm{kJ} / \mathrm{mol}) \\
298.15 \mathrm{~K}\end{array}$ & $\begin{array}{c}2,4-\mathrm{D} \\
\text { Average } \mathrm{X}(\mathrm{kJ} / \mathrm{mol}) \\
298.15 \mathrm{~K}\end{array}$ \\
\hline $\mathrm{S}_{1}$ & 966.198 & 880.401 \\
\hline $\mathrm{S}_{2}$ & 982.243 & $1,219.434$ \\
\hline $\mathrm{S}_{3}$ & 981.579 & $1,247.428$ \\
\hline $\mathrm{S}_{4}$ & $1,076.642$ & $1,172.980$ \\
\hline $\mathrm{S}_{5}$ & $1,009.510$ & $1,405.050$ \\
\hline $\mathrm{S}_{6}$ & $1,044.887$ & $1,062.569$ \\
\hline
\end{tabular}

Table 5. Equilibrium constants and standard free energy change at three different temperatures for adsorption of metolachlor on the selected soil samples

\begin{tabular}{|c|c|c|c|c|c|c|}
\hline \multirow{2}{*}{ Soil } & \multicolumn{2}{|c|}{$\mathrm{T}_{1} \mathrm{~K}$} & \multicolumn{2}{c|}{$\mathrm{T}_{2} \mathrm{~K}$} & \multicolumn{2}{c|}{$\mathrm{T}_{3} \mathrm{~K}$} \\
\cline { 2 - 7 } & $\ln _{\mathrm{o}}$ & $\Delta \mathrm{G}^{\mathrm{o}}(\mathrm{kJ} / \mathrm{mol})$ & $\ln _{\mathrm{o}}$ & $\Delta \mathrm{G}^{\mathrm{o}}(\mathrm{kJ} / \mathrm{mol})$ & $\ln _{\mathrm{o}}$ & $\Delta \mathrm{G}^{\mathrm{o}}(\mathrm{kJ} / \mathrm{mol})$ \\
\hline $\mathrm{S}_{1}$ & 0.508 & -1.196 & 0.308 & -0.762 & 0.268 & -0.699 \\
\hline $\mathrm{S}_{2}$ & 0.594 & -1.399 & 0.296 & -0.733 & 0.195 & -0.507 \\
\hline $\mathrm{S}_{3}$ & 0.405 & -0.952 & 0.311 & -0.770 & 0.036 & -0.095 \\
\hline $\mathrm{S}_{4}$ & 0.608 & -1.431 & 0.315 & -0.781 & 0.064 & -0.168 \\
\hline $\mathrm{S}_{5}$ & 0.547 & -1.288 & 0.372 & -0.921 & 0.137 & -0.357 \\
\hline $\mathrm{S}_{6}$ & 0.552 & -1.300 & 0.452 & -1.120 & 0.105 & -0.273 \\
\hline
\end{tabular}

Table 6. Equilibrium constants and standard free energy change at three temperatures for adsorption of 2,4-D on the selected soil samples

\begin{tabular}{|c|c|c|c|c|c|c|}
\hline \multirow{2}{*}{ Soil } & \multicolumn{2}{|c|}{$\mathrm{T}_{1} \mathrm{~K}$} & \multicolumn{2}{c|}{$\mathrm{T}_{2} \mathrm{~K}$} & \multicolumn{2}{c|}{$\mathrm{T}_{3} \mathrm{~K}$} \\
\cline { 2 - 7 } & $\operatorname{lnK}_{\mathrm{o}}$ & $\Delta \mathrm{G}^{\mathrm{o}}(\mathrm{KJ} / \mathrm{mol})$ & $\operatorname{lnK}_{\mathrm{o}}$ & $\Delta \mathrm{G}^{\mathrm{o}}(\mathrm{KJ} / \mathrm{mol})$ & $\operatorname{lnK}_{\mathrm{o}}$ & $\Delta \mathrm{G}^{\mathrm{o}}(\mathrm{KJ} / \mathrm{mol})$ \\
\hline $\mathrm{S}_{1}$ & 0.504 & -1.187 & 0.1459 & -0.362 & 0.018 & -0.049 \\
\hline $\mathrm{S}_{2}$ & 0.574 & -1.350 & 0.196 & -0.485 & 0.086 & -0.225 \\
\hline $\mathrm{S}_{3}$ & 0.698 & -1.643 & 0.534 & -1.323 & 0.122 & -0.319 \\
\hline $\mathrm{S}_{4}$ & 0.594 & -1.397 & 0.521 & -1.291 & 0.250 & -0.651 \\
\hline $\mathrm{S}_{5}$ & 0.869 & -2.048 & 0.318 & -0.780 & 0.081 & -0.212 \\
\hline $\mathrm{S}_{6}$ & 0.547 & -1.289 & 0.402 & -0.995 & 0.309 & -0.803 \\
\hline
\end{tabular}


Table 7. Standard enthalpy change and standard entropy change (determined graphically) for adsorption of metolachlor and 2,4-D on the selected soil samples

\begin{tabular}{|c|c|c|c|c|c|c|}
\hline \multirow{2}{*}{ Soil } & \multicolumn{3}{|c|}{ metolachlor } & \multicolumn{3}{c|}{$2,4-\mathrm{D}$} \\
\cline { 2 - 7 } & $\Delta \mathrm{H}^{\mathrm{o}}(\mathrm{kJ} / \mathrm{mol})$ & $\mathrm{R}^{2}$ & $\Delta \mathrm{S}^{\mathrm{o}}(\mathrm{J} / \mathrm{mol} \cdot \mathrm{k})$ & $\Delta \mathrm{H}^{\mathrm{o}}(\mathrm{kJ} / \mathrm{mol})$ & $\mathrm{R}^{2}$ & $\Delta \mathrm{S}^{\mathrm{o}}(\mathrm{J} / \mathrm{mol} \cdot \mathrm{k})$ \\
\hline $\mathrm{S}_{1}$ & -5.954 & 0.889 & -16.998 & -12.019 & 0.944 & -38.525 \\
\hline $\mathrm{S}_{2}$ & -9.884 & 0.940 & -30.198 & -12.074 & 0.924 & -38.195 \\
\hline $\mathrm{S}_{3}$ & -9.016 & 0.959 & -28.199 & -14.021 & 0.928 & -43.352 \\
\hline $\mathrm{S}_{4}$ & -13.353 & 0.999 & -42.127 & -8.356 & 0.883 & -24.294 \\
\hline $\mathrm{S}_{5}$ & -10.048 & 0.988 & -30.832 & -19.491 & 0.959 & -61.976 \\
\hline $\mathrm{S}_{6}$ & -10.881 & 0.890 & -33.485 & -5.887 & 0.990 & -16.292 \\
\hline
\end{tabular}

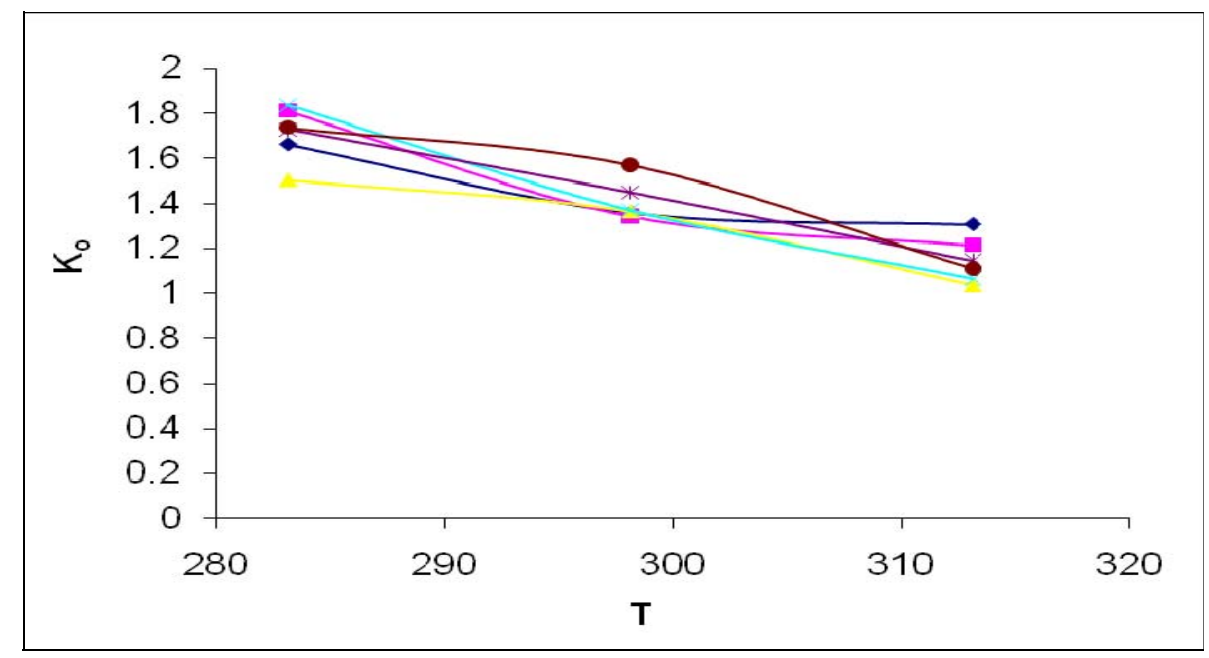

(a)

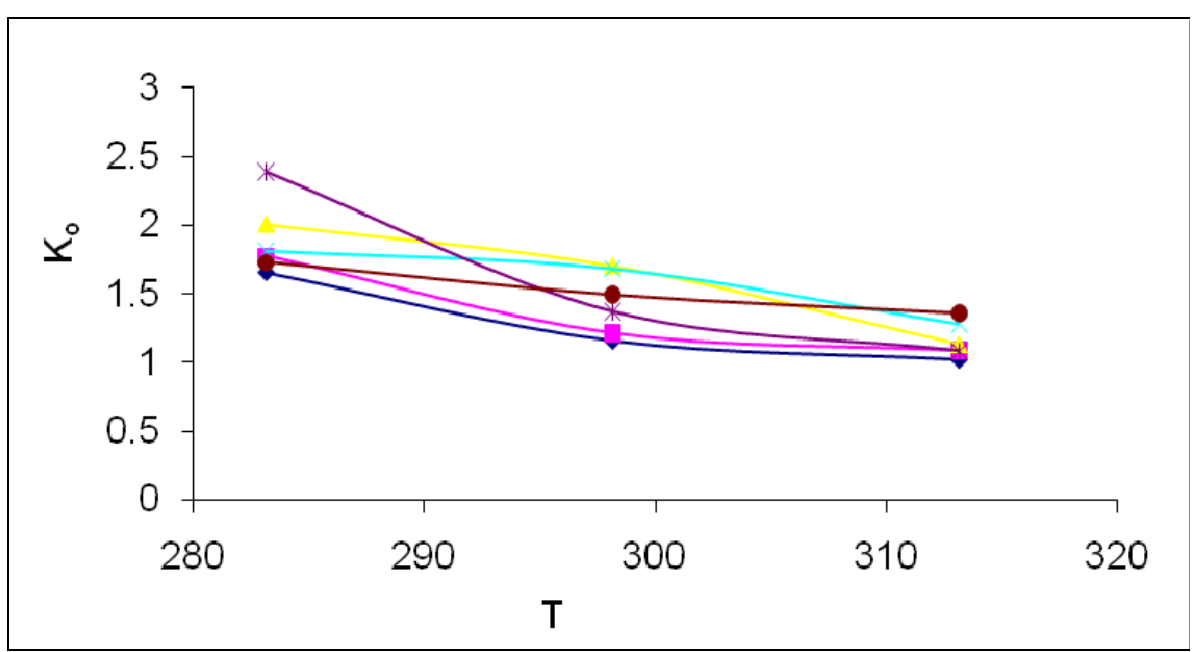

(b)

Figure 1. Variation of equilibrium rate constant with $\left(\mathrm{K}_{\mathrm{o}}\right)$ Temperature $(\mathrm{T})$ for, (a) metolachlor (b) 2,4-D on the six selected soil samples $\left(\bullet \mathrm{S}_{1}, \boldsymbol{-} \mathrm{S}_{2}, \boldsymbol{\Delta} \mathrm{S}_{3}, \mathrm{x}_{4}, * \mathrm{~S}_{5}, \bullet \mathrm{S}_{6}\right)$ 


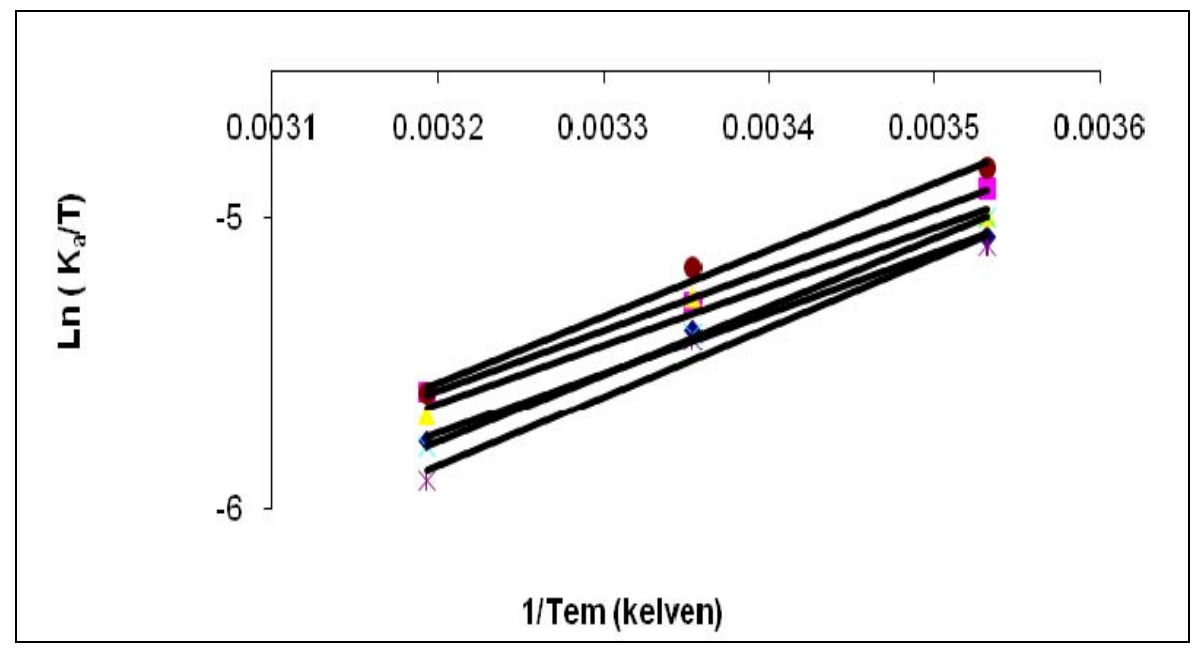

(a)

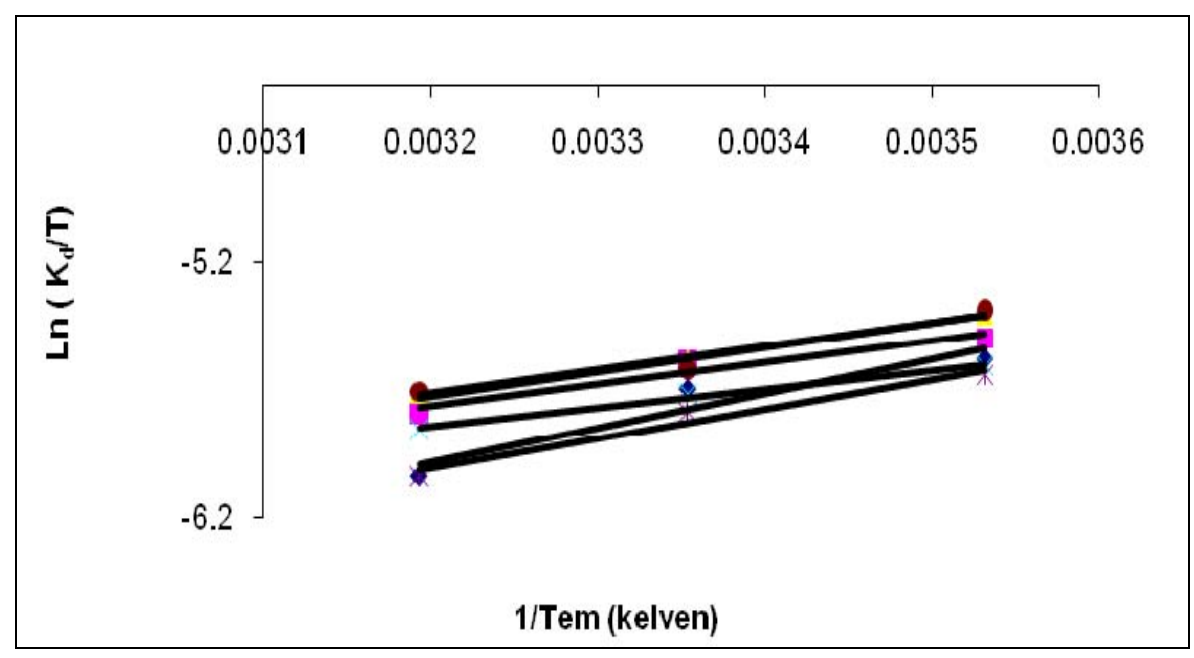

(b)

Figure 2. Variation of $\ln \left(\mathrm{K}_{\mathrm{a}} / \mathrm{T}\right)$ with $1 / \mathrm{T}$ for metolachlor of, (a) adsorption o (b) desorption o on the six soil samples $\left(\bullet \mathrm{S}_{1}, \boldsymbol{\bullet} \mathrm{S}_{2}, \boldsymbol{\Delta} \mathrm{S}_{3}, \mathrm{x} \mathrm{S}_{4}, * \mathrm{~S}_{5}, \bullet \mathrm{S}_{6}\right)$

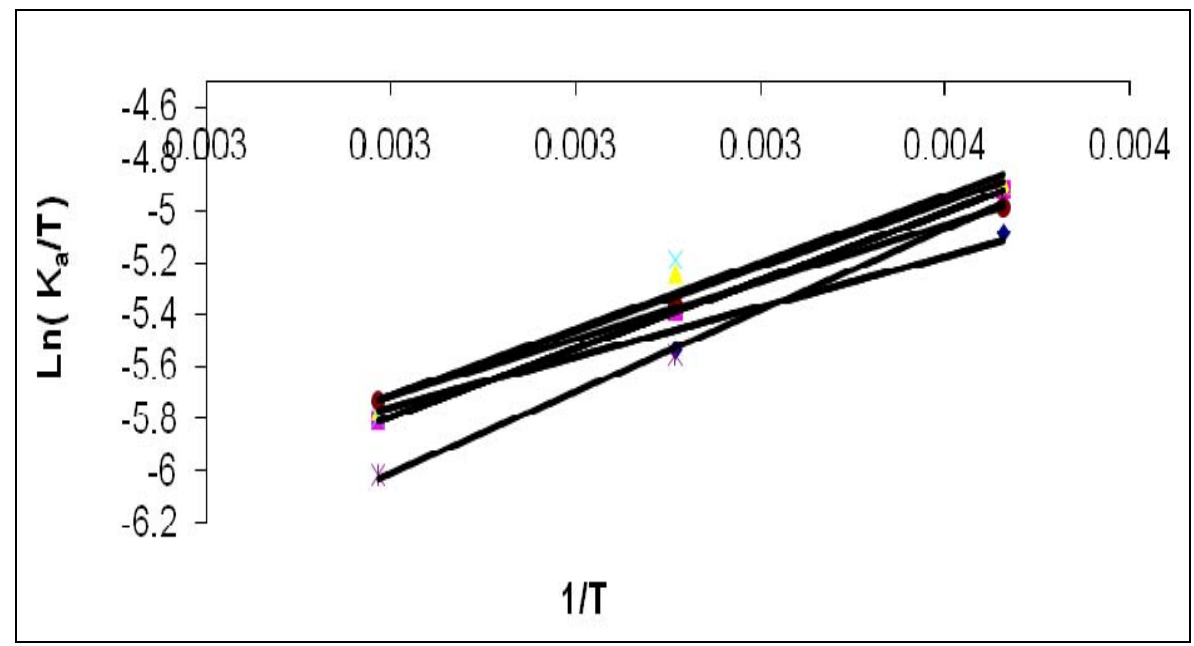

(a) 


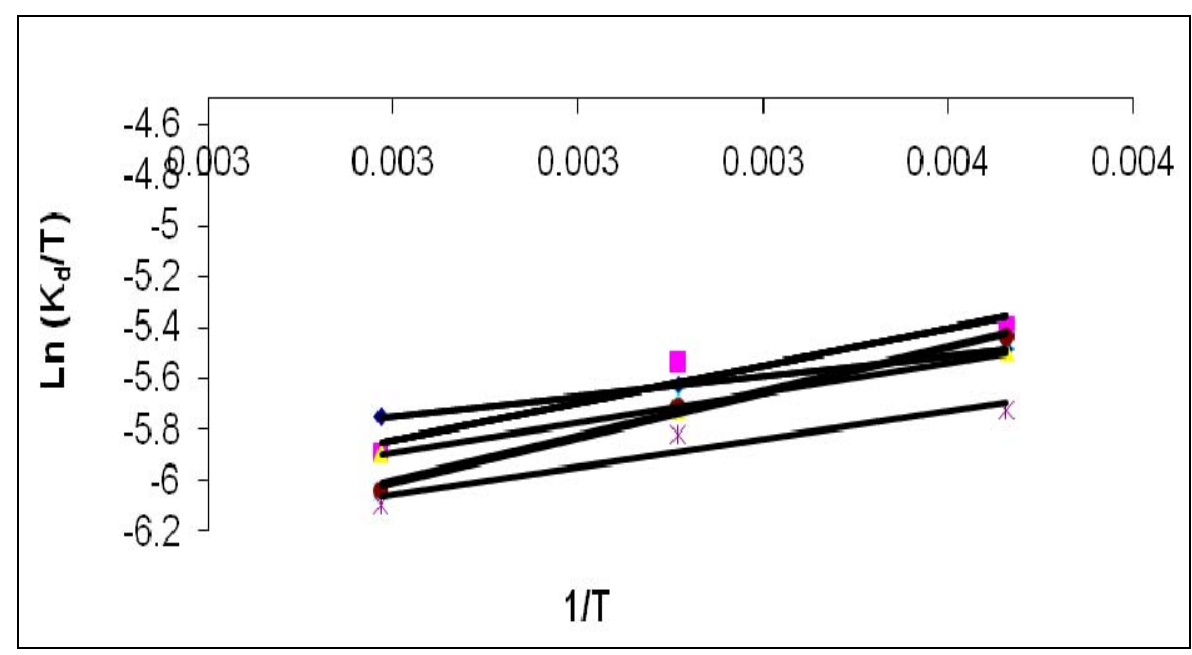

(b)

Figure 3. Variation of $\ln \left(\mathrm{K}_{\mathrm{a}} / \mathrm{T}\right)$ with 1/T for 2,4-D of, (a) adsorption (b) adsorption on the six soil samples $\left(\mathrm{S}_{1}\right.$, - $\left.\mathrm{S}_{2}, \boldsymbol{\Delta} \mathrm{S}_{3}, \mathrm{x}_{4}, * \mathrm{~S}_{5}, \bullet \mathrm{S}_{6}\right)$ 